\title{
Formation and treatment features of oil-fields waste water
}

\author{
Evgeny Alekseev* \\ Moscow State University of Civil Engineering (MGSU) National Research University, 129337, \\ Moscow, Russia
}

\begin{abstract}
The oil-fields development and operation can be associated with high water consumption and waste water emission. Most of the pollutants come from drilling and formation waters. At the same time, a significant proportion of solid dispersed pollutants is accounted for drilling waste water. Formation waters are the main source of oil contaminants. The technological processes of oil-field waste water treatment are based on gravity separation. In the context of increasing the environmental requirements for production activities, especially in the regions with low average annual temperatures and, accordingly, slow processes of ecosystems' self-cleaning, the problem of environment reliable protection arises. Gravity separation methods cannot provide the required quality of waste water treatment. Modern achievements in the field of baromembrane technologies and high salinity of waste water make it most effective and expedient to use membrane and electrochemical methods of waste water treatment.
\end{abstract}

\section{Introduction}

The oil industry is characterized by significant water consumption and is the source of a large amount of waste water. Water consumption for the main technological processes can reach $5 \mathrm{~m}^{3}$ for 1 ton produced oil. The peculiarity of oil production enterprises is their large dispersion over the territory of the oil-bearing region.

In this regard, maintaining the normal ecological state of nature and protecting water resources in the areas of oil-fields is an important and urgent problem.

The oil-fields development and reclamation can be associated with well drilling. A large amount of water is used during drilling operations, which leads to the waste water flows occurrence, united by the concept drilling waste water. On average, the total amount of drilling waste water is $1000 \mathrm{~m}^{3}$ for every $1000 \mathrm{~m}$ well penetration.

\section{Main part}

The composition of drilling waste water can vary greatly, depending on the geological conditions of drilling, the drugs and reagents used, and the drilling technology. In general, drilling waste water is a multicomponent polydisperse hetero-phase aqua system.

By the contamination degree, drilling waste water can be classified into two groups concentrated and slightly contaminated. 
Concentrated waste water is formed directly in the process of drilling wells using drilling mortars. As a result of their use, streams of a suspension containing bentonite and other dispersed impurities are formed. Suspensions discharged from drilling rigs are entitled to compaction in gravity separators. Waste water from gravity separators is the main flow of drilling waste water. In addition, washing-off from technological equipment, irrigation waste water from technological sites, spills of process fluids, etc. enter the stream of concentrated waste water.

Low-contaminated waste water is mainly diverted from the cooling systems of drilling equipment. The composition of pollutants contains oil products and dispersed impurities in the quantities that allow their reuse.

In modern oil production practice, water flooding is used to maintain reservoir pressure. The principle of water flooding is to pump water into the reservoir at high pressure. This is the most reliable and cost-effective way to increase well production rates. During the oilfields development with water flooding of an oil reservoir in the initial period of operation, the amount of formation water produced with oil slightly decreases. However, in the future, due to the rapid movement of the oil-water contact, some areas of the reservoir are flooded. As the oil-water contact advances, the production of an increasing number of wells starts watering out. With forced withdrawal of fluid with large masses of water, residual oil is extracted from the depths and, thus, the watered areas of the oil reservoir are fully exhausted.

Over time, in the fields developed with water flooding, the amount of water produced with oil increases significantly. The water content in oil can reach $80 \%$, that is, with each $1 \mathrm{~m}^{3}$ produced oil is withdrawn from the water reservoir $4 \mathrm{~m}^{3}$. At the oil gathering and preparation stations, water is mainly separated. As a result, the main share in the total amount of waste water in oil-fields is formation waters, produced together with oil. A distinctive feature of formation waters is high salinity, especially during the initial period of wells operation. In addition to salts, these waters contain coarse mineral impurities, oil and dissolved gases.

Significant pressure on the ecological system in the areas of oil-fields is created by atmospheric waters, coming from the territories of wells, demulsification plants, commodity parks, loading racks and their equipment [1].

Other less significant sources of waste water formation in oil-fields include production wells (washing sand plugs, water-off sites during repair work), compressor and diesel stations, the head node of the oil pipeline with an oil pumping station and tanks, pipe bases, garages, workshops [2,3]. The general flow of waste water from oil-fields also receives industrial water used in the processes of dehydration, desalting and stabilization of unrefined oil, as well as from cleaning tanks and water-off equipment. These include bottom-line waste water, formed as a result of air moisture condensation at the border with the oil surface and wash water, formed during storage tanks cleaning [4]. The listed sources form a common flow industrial waste water oil-fields.

In terms of physical and chemical indicators, waste water from oil-fields has significant differences. The color of waste water depends on the composition of oil impurities, the presence of micro dispersed particles of clay, iron and other substances. The formation water temperature can reach $60-90^{\circ} \mathrm{C}$.

The content of oil and mechanical impurities in waste water from oil-fields varies greatly and depends on local conditions. It does not remain constant and can change not only according to the season, but also during the day. On average, formation waters contain $1,5-3 \mathrm{~g} / \mathrm{dm}^{3}$ oil.

The presence of oil in waste water is due entirely to its preparation technology perfection. The use of highly effective reagents - demulsification agents can significantly reduce the pollution of waste water with emulsified oil. 
The total salinity and ionic composition of waste water depends on the geological age and stratigraphic position of the oil reservoir. By the salinity value, waste water is divided into sub-saline water with dissolved solids from 1 to $6 \mathrm{~g} / \mathrm{dm}^{3}$, salty - dissolved solids from 6 to $150 \mathrm{~g} / \mathrm{dm}^{3}$ and salinous - dissolved solids from 150 to $250 \mathrm{~g} / \mathrm{dm}^{3}$. According to the ionic composition, formation waters are divided into "hard" (chloride-calcium) and alkaline (hydro-carbonate-sodium).

The presence of mechanical impurities in formation waste water is due to various reasons, the main ones of which are:

- suffusion of productive strata;

- mixing of formation waters of different types in oil gathering systems;

- field equipment corrosion;

- chemical reactions of salts contained in waste water with reagents used for demulsification;

- use of contaminated process water in oil desalination processes.

The composition and properties of mechanical impurities are determined by the technological features of oil preparation, quality of fresh water used for technological needs. In hydrogen sulphide formation waste waters, mechanical impurities are in the form of colloidal and suspended particles, represented mainly by sulphureous iron. Most of the iron sulfide is in the water in the form of separate aggregates of various sizes.

The indicators of the waste water main flows from oil-fields depend on the geological conditions of the oil production area, the applied technological processes and equipment.

The difference in the values of the indicators reaches 100 or more-fold. The generalized indicators of waste water from oil-fields are as follows:

- active reaction of the environment, $\mathrm{pH}-6.2-8.7 \mathrm{~g} / \mathrm{dm}^{3}$;

- water density - 1.01-1.15 kg/ $\mathrm{dm}^{3}$;

- solid coarse impurities - 0.15-11.5 g/ $\mathrm{dm}^{3}$;

- oil and oil products $-0.1-5.0 \mathrm{~g} / \mathrm{dm}^{3}$;

- total mineralization - $15-180 \mathrm{~g} / \mathrm{dm}^{3}$;

- surface active agents $-30-150 \mathrm{~g} / \mathrm{dm}^{3}$;

The formation of waste water treatment systems for oil-fields is determined by many factors [5]. The most important ones are as follows:

- quantity and magnitude of various waste water streams;

- possibility and economic feasibility of extracting impurities;

- requirements for the indicators of treated water for reuse, return to production or discharge into a water body;

- availability of centralized drainage systems and treatment facilities;

- the presence of a water body, its hydrological and ecological indicators, the distance to it.

The currently widespread scheme of the waste water main streams purification from oilfields is shown in Figure 1. The peculiarity of these waste water types is the content of light fractions of oil and associated gas, which create a fire hazard. To prevent fires at treatment facilities, they are provided in a closed design.

All technological elements of the given scheme are the gravity separators with filtration at the end of the water purification process. Such a set of technological stages cannot provide high quality waste water treatment from micro-dispersed and emulsified impurities and reduce water salinity. In addition, large volumes of heavily watered sediments and sludge are formed during gravity separation.

The need for a large amount of water to maintain reservoir pressure necessitates the use of treated formation water for these purposes, which is especially important in low-water regions. The produced water turnover significantly reduces the technogenic environmental load in the territory. To increase oil recovery from old fields, involve low-permeability 
reservoirs in the development and increase the overhaul period of injection wells, deep purification of waste water is required: residual oil and solid particles no more than $10 \ldots 15$ $\mathrm{mg} / \mathrm{dm}^{3}[6,7]$ Moreover, their dimensions should not exceed $0.2 \ldots 1.0$ microns. This requires the introduction of new, more advanced technologies for water treatment for waterflooding. Such efficiency of waste water treatment can be achieved using physicochemical separation processes, for example, ultrafiltration and electrochemical flotation. [8].

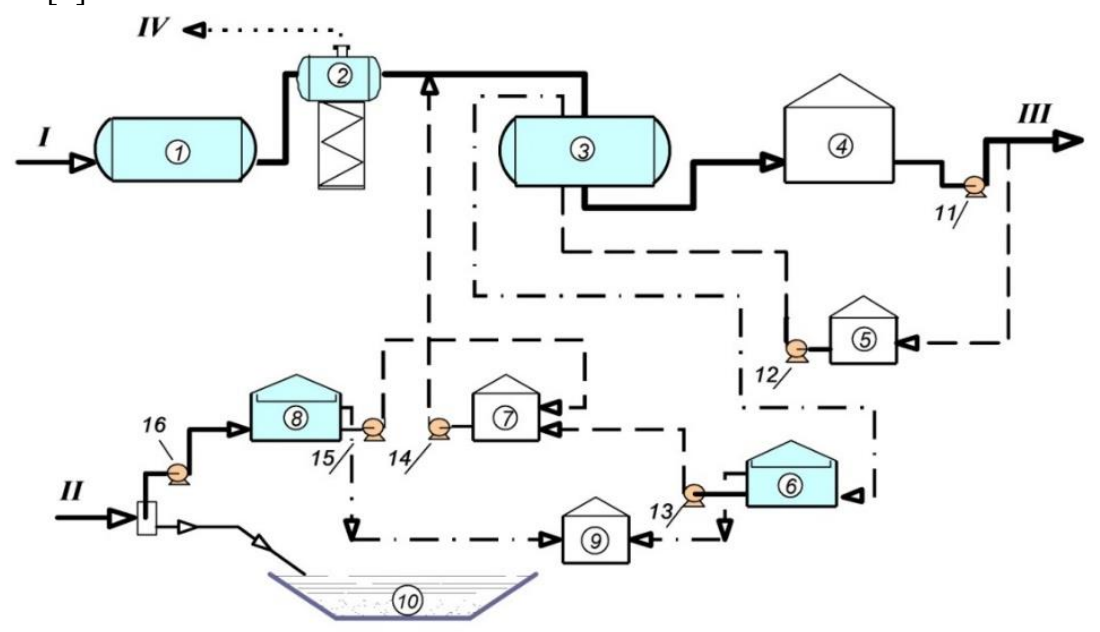

Fig. 1. Scheme of oil-field waste water treatment: $\boldsymbol{I}$ - formation waters; $\boldsymbol{I I}$ - industrial and atmospheric waters; III - water to the waterflooding system; IV - combustion gases; 1 - pressure horizontal subsiding tank; 2 - degasser; 3 - pressure quartz filters; 4 - reservoir for purified water; 5 water reservoir for washing filters; 6 - reservoir-settling tank for dirty wash water of filters; 7 intermediate tank of pre-treated water; 8 - settling tank for industrial and storm water; 9 - storage capacity of sediments and sludge; 10 - buffer tank; 11 - pumps for water supply to the waterflooding system; 12 - pumps of the quartz filter washing system; 13 - pumps for supplying wash water after settling; 14 - pumps for supplying pre-purified water for filtration; 15 - pump for supplying industrial and atmospheric water after settling; 16 - pump for supplying industrial and atmospheric water to the settling tank.

\section{Conclusion}

The use of new technological processes for treating waste water from oil-fields is of particular importance in the Arctic oil-fields development and in other areas with low temperatures. This is due to the increased viscosity of liquid saturated media at low temperatures and, as a consequence, a decrease in the gravitational separation efficiency. The high salinity of the formation water determines water high electrical conductivity. In this regard, it seems appropriate to use electrochemical and baromembrane processes for the reservoir and industrial waste water treatment.

\section{References}

1. V.I. Kichigin, Drainage systems of industrial enterprises: textbook (House of the Association of Civil Engineering Universities, Moscow, 2011).

2. V.V. Andreev, K.R. Urazakov, V.U. Dalimov and others, Oil Production Handbook (LLC "Nedra-Business Center", Moscow, 2000). 
4. I.M. Gabbasova, Journal of Water Resource and Protection. January 02 (04), 309-313 (2010).

5. Fakhru'l-Razi Ahmadun, Alireza Pendashteh, Luqman Chuah Abdullah, Dayang Radiah Awang Biak, Sayed Siavash Madaeni, Zurina Zainal Abidin, Journal of Hazardous Materials 170, 530-551 (2009).

6. R.B. Fattakhov, V.P. Tronov, A.V. Tronov, All-Russian scientific and technical conference "Big oil, realities, problems, prospects", October 15-18, Almetyevsk, pp. 189-195 (2001).

7. A.A. Pashayan, A.V. Nesterov, Ecology and Industry of Russia 5, 32-35 (2008).

8. E.V. Alekseev, E3S Web of Conferences 126, 00069 (2019). 